\title{
Developing Online Communities for Librarian Researchers: A Case Study
}

\section{Lili Luo, Marie Kennedy, Kristine Brancolini, and Michael Stephens}

\begin{abstract}
This study examines the role of online communities in connecting and supporting librarian researchers, through the analysis of member activities in the online community for academic librarians that attended the 2014 Institute for Research Design in Librarianship (IRDL). The 2014 IRDL cohort members participated in the online community via Twitter and a Facebook group page. A content analysis of their posts and an online survey among them identified different patterns of engagement and four primary types of content-posts related to completing the IRDL research project required for each cohort member, announcements about research-related resources and opportunities, posts reminiscing about the IRDL experience, and arrangements of conference attendance and meetups. Implications for successfully designing online communities for librarian researchers are discussed.
\end{abstract}

\section{Introduction}

Academic libraries emphasize research and scholarship by librarians. As early as 1972, ACRL's “Joint Statement on Faculty Status of College and University Librarians" highlighted librarians' research roles in both professional interests and work responsibilities. ${ }^{1}$ Research serves to create new knowledge and therefore contribute to the growth of academic librarianship, and it is needed to "improve problem solving and decision making in the workplace, to make professional practitioners critical consumers of the research literature, and to better equip librarians to provide optimal information services to researchers in other fields." ${ }^{2}$

Given the well-acknowledged significance of research in academic libraries, it is crucial to understand how to promote the research culture and research-mindedness among academic librarians. Online communities provide a venue for librarian researchers to share information, provide/receive social support, and experience camaraderie. They may serve as a platform to spread the culture of research and scholarship across the profession. In this paper, we present a case study of an online community of librarian researchers developed from the Institute for Research Design in Librarianship (IRDL).

\footnotetext{
*Lili Luo is an Associate Professor in the School of Information at San Jose State University; e-mail: lili.luo@ sjsu.edu. Marie Kennedy is Serials and Electronic Resources Librarian at Loyola Marymount University Library; e-mail: Marie.Kennedy@lmu.edu. Kristine Brancolini is Dean of the Library, Loyola Marymount University Library; e-mail: brancoli@lmu.edu. Michael Stephens is an Assistant Professor in the School of Information at San Jose State University; e-mail: michael.t.stephens@sjsu.edu. This research was supported in part by a grant from the Institute of Museum and Library Services (RE-06-13-0060-13). (02017 Lili Luo, Marie Kennedy, Kristine Brancolini, and Michael Stephens, Attribution-NonCommercial (http:// creativecommons.org/licenses/by-nc/4.0/) CC BY-NC.
} 
IRDL is a three-year program funded by the Institute of Museum and Library Services (IMLS) that provides continuing education opportunities for a selected group of academic librarians to enhance their research skills and output and to increase the scope and value of academic library research. It also seeks to increase the research confidence of participants by providing both mastery experiences and social persuasion. According to Bandura, ${ }^{3}$ mastery experiences build confidence through success and provide an individual with the ability to persevere in the face of obstacles, which is especially important in performing difficult tasks. Social persuasion consists of structuring situations in which an individual receives encouragement and experiences success in working through challenges. The centerpiece of IRDL is a nine-day summer research workshop, where academic and research librarians develop the skills necessary to complete a research study of their design during the coming year. IRDL's learning objectives include the following items:

- Write effective research questions and hypotheses

- Choose an appropriate research design for a library science study

- Conduct a literature review

- Explain the conceptual logic behind various data collection approaches and describe the rationale for selection of specific methods

- Identify appropriate sampling strategies for research projects

- Use and apply commonly used qualitative data collection methods

- Assess and apply different qualitative data analysis options

- Design and implement a survey

- Understand survey data management

- Explain various analytic options for surveys

- Understand basic principles of mixed methods research design

- Choose an appropriate research dissemination forum

- Write and disseminate an effective research report

- Access and participate in the Institute virtual community and related networks for support during the research process

Participants' collaborative learning experiences during the time of IRDL reinforce the learning goals and begin to create a community of practice. In the following year, ongoing support via an online community is provided to assist IRDL participants in conducting and disseminating their research study. In this case study, we seek to answer the following research question: What is the role of online communities in helping librarian researchers communicate and connect with each other and support each other in their research process?

\section{Literature Review}

The literature review focuses on three areas: importance of academic library research, barriers to librarians' research engagement, and online community. The purpose of the literature review is to provide a context for this study. The widely-recognized value of academic library research speaks to the necessity for academic librarians to conduct research. The existing barriers documented in the literature prompt us to explore new ideas (such as the online community of librarian researchers) to overcome them. The review of online community literature in other disciplines serves as the theoretical and methodological foundation where we could build our own study in examining an online community of librarian researchers.

A frequently used definition of research in academic library literature was provided by Peritz (1980): "an inquiry which is carried out, at least to some degree, by a systematic method with the purpose of eliciting some new facts, concepts, or ideas." The importance of research in academic libraries is well documented. Hernon and Schwartz ${ }^{4}$ 
stated that research "can and should provide insights and guidance into how well library programs, services, and collections function, especially in making libraries more responsive service organizations." Crumley and Koufogiannakis ${ }^{5}$ believed an analytical examination of librarianship through research fosters growth, curiosity, and awareness, promoting new learning. Haddow and Klobas ${ }^{6}$ opined that effective interaction between research and practice would produce a strong theoretical framework within which a practitioner community can develop and thrive. Neal ${ }^{7}$ emphasized the need for academic librarians to pursue research that advances knowledge at the individual, organization, professional, and national levels. Perkins and Slowik ${ }^{8}$ reviewed ACRL's "Standards for College Libraries" in the past half-century and pointed out that the professional standards have clearly confirmed the importance of inquiry and research activities such as scholarly publication, presentation of papers, and reviews of books and set the line for determining research quality of academic librarians so that their world could be more easily translatable to the academic community as a whole.

In terms of the specific benefits of engaging in research, Montanelli and Stenstrom ${ }^{9}$ specified that the value of research for academic librarians included job promotion, personal acknowledgement, enriched relationships with teaching faculty, increased ability to change, and better library service through shared knowledge and experience. Similarly, through a study of scholarly e-journals, DuBose and Durant ${ }^{10}$ noted that the advantages of research for academic librarians included delineation of research subjects, collaboration with others, improved understanding and application to daily issues, and their own changing development as librarians. Perkins and Slowik ${ }^{11}$ interviewed 23 academic library administrators regarding their perceived value of research in their university/college libraries. Their findings echoed the literature; the benefits of librarians' research identified in their study included fulfilling tenure-track requirements, library faculty recognition, improved services and programs, and improved knowledge of the research field.

Despite the recognition of the value for academic librarians' conducting and applying research, it appears that research has not been sufficiently involved in library practice. ${ }^{12}$ McKechnie, Julien, and Oliphant ${ }^{13}$ conducted a study that examined if and how research results are being interpreted and reported for application to the work of LIS practitioners and found that, although 59 percent of papers included implications for practice, more than half used vague, general, or otherwise unclear statements rather than explicit delineation of implications for practice.

Concerns have been raised that there is a gap between LIS research and practice. ${ }^{14}$ Waldhart ${ }^{15}$ stated that research had limited impact on the profession because "much of the research is artificially contrived, or too specific, esoteric, or dated to be relevant to real-life problems facing the library community." Powell et al. ${ }^{16}$ noticed from the literature that the publication of LIS research articles has been spotty and shows a stable or declining publication pattern. The lack of time, support, and incentives for practitioners to engage in research has been cited frequently as a factor for the lack of research involvement among practitioners. ${ }^{17}$ The library profession was criticized for being overly focused on practice and lack of "research-mindedness."18 Most practitioners had little interest in conducting research, ${ }^{19}$ and the profession was considered to be "poorly equipped to recognize and strive for research quality." 20

To address the research-practice divide, several solutions have been proposed. Basker $^{21}$ suggested that, in the workplace, librarians be provided with assistance in identifying ideas for research, mentoring by an experienced researcher, financial support, time to do research, rewards for completing research in a timely fashion, assistance in matching research projects with personal development, and encouragement to apply the results of research. Watson-Boone ${ }^{22}$ advocated for the concept of 
"practitioner-researchers" and synthesized six research approaches from the literature to help librarians gain understanding and advance knowledge. Crowley ${ }^{23}$ suggested that the collaboration between researchers, consultants, and practitioners (such as practitioners serving as adjunct faculty in LIS degree programs) should be reinforced for theory development and research production.

In addition to the above suggestions, we propose that relevant and vibrant online communities will also help foster the research culture and research-mindedness and offer a sense of belonging to academic librarians as they strive to become librarian researchers. In this study, through the analysis of librarians' involvement in the IRDL online community, we hope to shed light on how to effectively develop online communities to support academic librarians' research and scholarship.

Online communities are defined as "cyberspace[s] supported by computer-based information technology, centered upon communication and interaction of participants to generate member-driven content, resulting in a relationship being built." ${ }^{24}$ Iriberri and Leroy ${ }^{25}$ reviewed the literature and identified the following benefits of online communities for individuals:

- Information exchange-access a to a wide variety of members, information, and experiences

- Social support-opportunity to provide/receive support, build and maintain social ties, and bond socially and generate social action

- Social interaction-opportunity to meet people and build friendships

- Time and location flexibility - flexible access to the community, flexible time management, and spatial and temporal independence

- Permanency - ability to edit responses, ability to archive and search messages, ability to establish permanent social presence through photographs and text, and ability to control one's level of participation in the community

Researchers in different disciplines have studied online communities with different emphases - in computer science, technology media and mechanisms is the focus; in sociology, physical versus virtual community comparisons have attracted most researchers; in management, the emphasis is on the value of user-generated content; in psychology, relationship and attachment among community members have been extensively investigated; in information systems, researchers have concentrated on development, implementations, outcomes, and applications of online communities. ${ }^{26}$ Multiple theories have also been adopted to examine online communities, such as technology acceptance model (TAM), trust theory, social cognitive theory, social capital theory, social learning theory, social network theory, commitment theory, and social influence theory. ${ }^{27}$

The area of online community research most relevant to our study is the exploration of determinants for online community success. Iriberri and Leroy ${ }^{28}$ proposed a model of online communities' lifecycle, consisting of inception, creation, growth, maturity, and death. For each stage, they identified several success factors. For example, at the inception stage, the success factors include purpose, focus, codes of conduct, trademark, and funding/revenue sources. Ludford et al., ${ }^{29}$ through an experiment about movie ratings, found that group similarity and uniqueness positively influenced participation and led to more visible content contribution. Wang, Chen and $\mathrm{Tsai}^{30}$ studied online community participation from three conceptual angles (social interaction, human computer interaction, and issue involvement); their findings revealed that member commitment to communities was influenced more by their issue involvement compared to their perceived social interaction or perceived system interactivity. Ren, Kraut, and Kiesler, ${ }^{31}$ on the premise that online communities depend on the commitment and voluntary participation of their members, examined members' attachment to the group 
via the theoretical lenses of common identity and common body and suggested ideas on design decisions for online communities.

In the library literature, using the search terms "library OR librarian" AND "online community," we have not been able to locate any empirical or theoretical research about online communities. We hope to fill that void via the analysis of librarians' activities in the IRDL online community.

\section{Case Study Design}

Case studies are "a way of organizing social data... to preserve the unitary character of the social object being studied... it is an approach which views any social unit as a whole." ${ }^{\prime 2}$ In this study, we employed the descriptive case study design to provide thorough descriptions and interpretations of a particular case - the IRDL online community for librarian researchers. ${ }^{33}$ The study design at the holistic and the embedded level is as follows:

- Holistic level. The first cohort of IRDL completed their training in June 2014; in the following academic year, the 25 cohort members established an online community to stay connected as they continue to conduct and disseminate research. They created the Twitter hashtag \#IRDL to share tweets and developed a Facebook group titled "IRDL Scholars." Their participation in the IRDL online community on Twitter and Facebook is investigated in this study. Ultimately, we hope to yield insights on developing effective online communities that are research-focused and could operate as a cohesive force to motivate and attract more librarians to engage in research, thus enhancing the quality and rigor of academic librarian research.

- Embedded level. The study consists of three components: 1) content analysis of the 2014 IRDL cohort members' public tweets related to IRDL; 2) content analysis of the cohort members' posts on the private "IRDL Scholars" Facebook group page; and 3) an online survey about the cohort members' perceptions of the Facebook group page. Twitter was chosen for the analysis because, during 2014 IRDL, the hashtag "\#IRDL" was created for cohort members to tweet about their IRDL thoughts and experiences, and many cohort members became connected on Twitter and tweeted actively during IRDL. We plan to study how they continued their interactions and connections on Twitter in the year following the onsite training at IRDL. The reason for choosing Facebook was self-evident-the private "IRDL Scholars" Facebook group page is the dedicated online community for IRDL cohort members. The online survey seeks to examine how the 2014 cohort members perceived their participation in the Facebook community and to identify the desirable elements in an online community of librarian researchers. The tweets and Facebook posts published between June 30, 2014, and June 30, 2015, a full year after the close of the 2014 IRDL onsite training, were selected for analysis. Inductive coding was conducted on a small sample of tweets and Facebook posts to establish the coding scheme respectively, and then deductive coding ensued for the rest of the analysis based on the coding scheme. The online survey was implemented using Qualtrics and was sent to all 25 cohort members. The response rate was 76 percent. Results of the content analysis and the online survey are presented in the next section.

Although case studies could provide a profound understanding of a case, they are widely criticized for lacking external validity because one case provides no basis for generalizing to a wider population beyond that case. This is an inherent weakness of case study design. ${ }^{34}$ 


\section{Results}

\section{Twitter}

Each member of the IRDL 2014 cohort has a Twitter account. Since the objective is to examine how the cohort members interact with each other as a community on Twitter, their tweets meeting the following criteria are included in the analysis: 1) containing the Twitter handle of any other cohort member; or 2) containing the hashtag \#irdl. The first criterion reflects how the cohort members remain connected after they leave IRDL, and the second one reveals their continuous thoughts and experiences related to IRDL. A total of 260 tweets meeting these two criteria were identified in the study timeframe.

Tweets are defined as all the content a user posts on Twitter, including original Twitter postings, retweets (with the prefix of RT or MT), and tweet replies. As shown in Table 1 , of the 25 cohort members, 18 posted tweets that met the study criteria.

\begin{tabular}{|l|c|c|c|c|}
\hline \multicolumn{5}{|c|}{ TABLE 1 } \\
Frequency Distribution of Cohort Members' Facebook and Twitter Posts \\
\hline $\begin{array}{l}\text { IRDL 2014 } \\
\text { Cohort Member }\end{array}$ & \# of Tweets & $\begin{array}{c}\text { \# of Facebook } \\
\text { Posts }\end{array}$ & $\begin{array}{c}\text { \# of Facebook } \\
\text { Likes }\end{array}$ & $\begin{array}{c}\text { \# of Facebook } \\
\text { Replies }\end{array}$ \\
\hline Member A & $0(0.0 \%)$ & $13(8.2 \%)$ & $17(3.6 \%)$ & $27(5.0 \%)$ \\
\hline Member B & $0(0.0 \%)$ & $0(0.0 \%)$ & $0(0.0 \%)$ & $0(0.0 \%)$ \\
\hline Member C & $11(4.2 \%)$ & $0(0.0 \%)$ & $2(0.4 \%)$ & $11(2.1 \%)$ \\
\hline Member D & $24(9.2 \%)$ & $21(13.2 \%)$ & $13(2.8 \%)$ & $91(17.0 \%)$ \\
\hline Member E & $21(8.1 \%)$ & $6(3.8 \%)$ & $41(8.7 \%)$ & $30(5.6 \%)$ \\
\hline Member F & $3(1.2 \%)$ & $5(3.1 \%)$ & $17(3.6 \%)$ & $9(1.7 \%)$ \\
\hline Member G & $1(0.4 \%)$ & $0(0.0 \%)$ & $12(2.5 \%)$ & $2(0.4 \%)$ \\
\hline Member H & $1(0.4 \%)$ & $42(26.4 \%)$ & $36(7.6 \%)$ & $126(23.6 \%)$ \\
\hline Member I & $0(0.0 \%)$ & $0(0.0 \%)$ & $0(0.0 \%)$ & $0(0.0 \%)$ \\
\hline Member J & $3(1.2 \%)$ & $4(2.5 \%)$ & $19(4.0 \%)$ & $18(3.4 \%)$ \\
\hline Member K & $17(6.5 \%)$ & $3(1.9 \%)$ & $9(1.9 \%)$ & $4(0.7 \%)$ \\
\hline Member L & $6(2.3 \%)$ & $1(0.6 \%)$ & $8(1.7 \%)$ & $2(0.4 \%)$ \\
\hline Member M & $39(15.0 \%)$ & $5(3.1 \%)$ & $26(5.5 \%)$ & $14(2.6 \%)$ \\
\hline Member N & $0(0.0 \%)$ & $11(6.9 \%)$ & $16(3.4 \%)$ & $29(5.4 \%)$ \\
\hline Member O & $0(0.0 \%)$ & $3(1.9 \%)$ & $33(7.0 \%)$ & $16(3.0 \%)$ \\
\hline Member P & $2(0.8 \%)$ & $0(0.0 \%)$ & $25(5.3 \%)$ & $1(0.2 \%)$ \\
\hline Member Q & $4(1.5 \%)$ & $8(5.0 \%)$ & $31(6.6 \%)$ & $32(6.0 \%)$ \\
\hline Member R & $21(8.1 \%)$ & $2(1.3 \%)$ & $8(1.7 \%)$ & $4(0.7 \%)$ \\
\hline Member S & $56(21.5 \%)$ & $8(5.0 \%)$ & $36(7.6 \%)$ & $50(9.3 \%)$ \\
\hline Member T & $0(0.0 \%)$ & $1(0.6 \%)$ & $7(1.5 \%)$ & $4(0.7 \%)$ \\
\hline Member U & $7(2.7 \%)$ & $2(1.3 \%)$ & $17(3.6 \%)$ & $6(1.1 \%)$ \\
\hline Member V & $15(5.8 \%)$ & $1(0.6 \%)$ & $4(0.8 \%)$ & $14(2.6 \%)$ \\
\hline Member W & $28(10.8 \%)$ & $14(8.8 \%)$ & $7(1.5 \%)$ & $18(3.4 \%)$ \\
\hline Member X & $0(0.0 \%)$ & $0(0.0 \%)$ & $38(8.1 \%)$ & $7(1.3 \%)$ \\
\hline Member Y & $1(0.4 \%)$ & $9(5.7 \%)$ & $49(10.4 \%)$ & $20(3.7 \%)$ \\
\hline Total & $260(100 \%)$ & $159(100 \%)$ & $471(100 \%)$ & $535(100 \%)$ \\
\hline
\end{tabular}


The top three contributors were member S, M, and W, who collectively posted 47.3 percent of the 260 tweets. In fact, close to two-thirds of the tweets were posted by only five members. In terms of monthly frequency distribution of the tweets, as shown in Figure 1, 41.5 percent of them were posted in July, the month immediately following the 2014 IRDL.

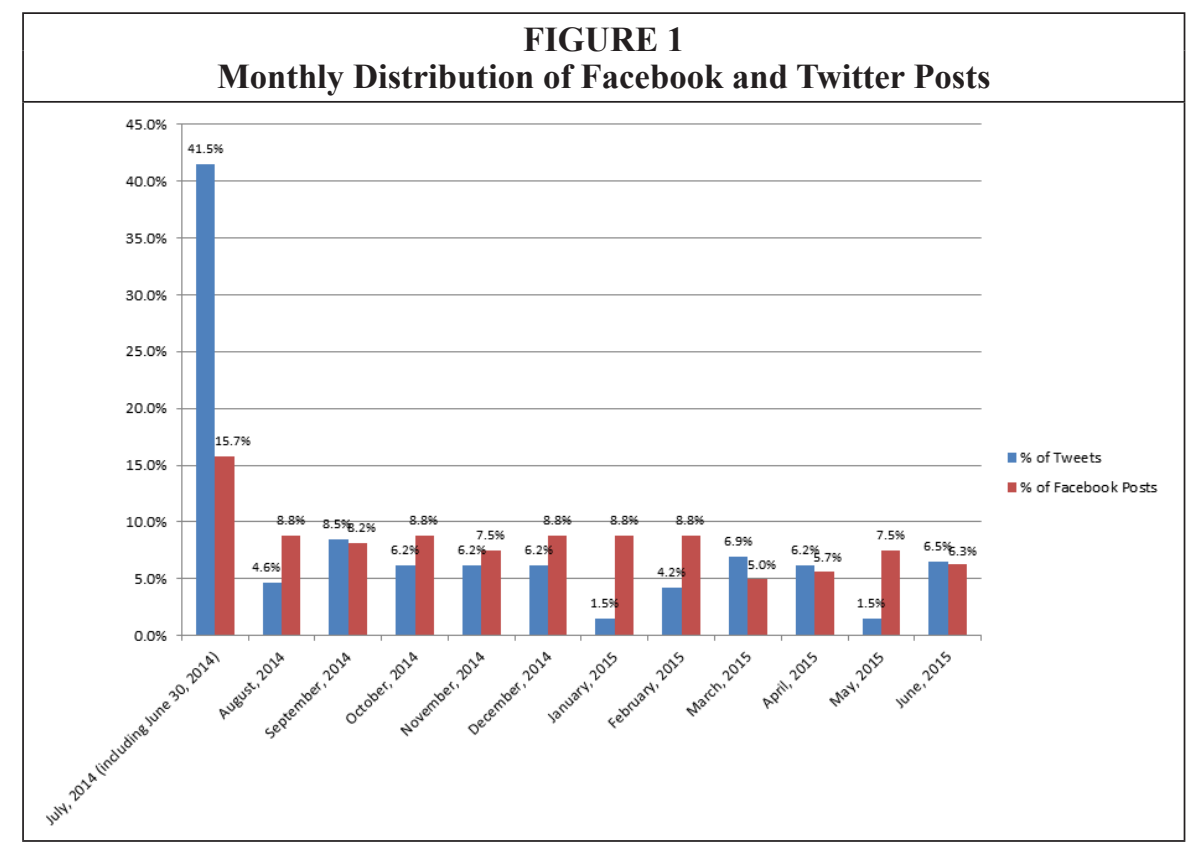

The content of the tweets can be grouped into the following categories:

- The majority of the tweets $(41.9 \%)$ were interactions between cohort members that were not related to research or IRDL. Instead, the tweets were about their personal life, work, and professional opinions/musings. Below are a few examples (all Twitter handles of the cohort members are anonymized):

$\square \quad$ One member saw a website related to another member's work, and tweeted, “@TwitterHandle, I thought of you. https://t.co/Ri5ldJFUbq"; the other member replied, “@TwitterHandle We've been in conversation with these folks about collaborating on a linked open data project! Thanks for thinking of me."

$\square \quad$ One member tweeted about being inspired by what another member did at work: "inspired by @TwitterHandle to create a Wikipedia LibGuide that will be this morning's \#makeithappen project"; the member got a reply from the other member: “@TwitterHandle \#nice \#dontworktoohard \#friday"

$\square \quad$ One member announced important personal news and received congratulations from other cohort members such as “@TwitterHandle Congrats!”

- Two members planned meetups via Twitter - one member posted, “@TwitterHandle Rumor has it you're coming to Knoxville for The Collective next February. It will be great to see you and catch up!" and the other member replied, “@TwitterHandle Indeed I am! I look forward to catching up re: research AND to gushing over your little one."

One member retweeted another member's tweet where he shared his opinion regarding a particular political issue: “RT @TwitterHandle: Dear Senator 
Ted Cruz, @sentedcruz I'm going to explain to you how Net Neutrality ACTUALLY works http://t.co/s2JlLvKv7F"

- The second most popular types of tweets (20.4\%) were those related to the individual research project that each cohort member is expected to complete as part of their IRDL training. These tweets included updates about their research project progress, questions regarding the project requirements, and issues/problems encountered when working on their project. Below are a few examples:

$\square \quad$ One member asked a procedural question about completing the research project, "Hey \#irdl-Are you adding IRB time to your project schedule? It is an important part of my process." The member received replies such as “@Twitter Yes-our institution's review process at the moment takes a minimum of six weeks - longer for a full review"

$\square \quad$ One member posted an update about her project progress: "Research proposal sent! Not $100 \%$ done but I'm out of time. Now the hard work of doing the research begins. \#irdl"

$\square \quad$ One member asked for help from another member in completing the research project: “@TwitterHandle Will you e-mail your slide showing the hierarchy of your research aim/object/questions/hyp/etc? Thankyouverymuch!” and another expressed appreciation for others' help: “@TwitterHandle @TwitterHandle Your proposals helped me figure out what to do with mine-THANKS! \#irdl"

$\square \quad$ One member posted a resource that might be of help to two other members' research project: “@TwitterHandle @TwitterHandle This looks useful for your lit reviews! http://t.co/kIItbHRHV5"

$\square \quad$ One member announced the news of an upcoming publication that resulted from several cohort members' collaborative work: “Check out @libraryleadpipe this week for work by myself and other brilliant minds! @TwitterHandle @TwitterHandle @TwitterHandle \#DitchTheSurvey"

- Tweets about cohort members' feelings and thoughts related to their IRDL experiences were in third place (15.8\%). Below are a few examples:

$\square \quad$ One member posted a picture of the IRDL certificate: “\#irdl Proudly displaying the certificate on my office bulletin board. [online image]"

$\square \quad$ One member reminisced about a leisure activity he shared with two other members at IRDL: “@TwitterHandle@TwitterHandle I'm in Colo. and have discovered Breckenridge Bourbon. I'm buying a bottle to bring home!"

$\square \quad$ One member expressed gratitude for IRDL: “Thanks to \#irdl, I am understanding, and able to critique, more of the presentations I attend."

口 Some members retweeted the post to help IRDL recruit the 2015 cohort: "RT @IRDLonline: The IRDL application center is open. Submit your proposal by February 1, 2015: http://t.co/3Wyoo6O7vM. \#irdl"

- In fourth place were conference tweets $(13.5 \%)$, where cohort members discussed how IRDL benefited their conference experiences, shared what they learned at conferences that might be of relevance to other members, or scheduled meetups with other members. Below are a few examples:

$\square \quad$ One member tweeted about becoming more aware of research methods at a conference because of IRDL: "Already heard surveys and focus groups mentioned at \#alaac14 and I'm being a total methods snob thanks to \#irdl"

$\square \quad$ One member shared a new research technique learned at a conference: "Interested to hear about \#photovoice used as a library assessment method at \#lac14 this morning cc \#irdl" 
$\square \quad$ Some members attempted to schedule meetups during a conference; for example, one member asked, “@TwitterHandle ditto. Coming to the IRDL meetup on Sunday?” and received a reply: “@TwitterHandle maybe, I have a meeting on Sunday in Sacramento, so I don't know if I can make it. Are you presenting today?"

- The final category consisted of research-related resources and opportunities that cohort members shared (8.8\%). Below are a few examples:

口 One member posted a resource about publication strategies: "Stretch, Reach, and Fall Back: great technique for targeting journals for your papers. \#irdl http://t.co/hyXzsx2wfy"

$\square \quad$ One member tweeted about findings in a published research study: "only $16 \%$ of the [LIS] articles analyzed in this study qualify as research. Survey is most used method. http://t.co/uohh2d1etp \#irdl"

$\square \quad$ One member shared a research opportunity with another, and they decided to pursue it together: “@TwitterHandle Have you seen this? It's right down the street from you: http://t.co/xFc90BgbIY. Interested in a proposal?”; “@ TwitterHandle I would be more interested if I had a co-presenter! Are you game?”; “@TwitterHandle Yes! That was my assumption. I should have stated it explicitly. Due date is Jan 7. Chat next week?"

\section{Facebook}

The closed Facebook group "IRDL Scholars" is an online community for the IRDL 2014 cohort to communicate and interact with each other. It was created on June 3, 2014, about two weeks before the start of IRDL, by a cohort member. Between June 2014 and June 2015, the group only consisted of 24 out of the 25 cohort members and the two IRDL project co-directors. Members of the IRDL 2015 cohort were invited to join the group in July 2015, and now the group has 66 members.

This analysis focused on the 2014 IRDL cohort members' posts on the Facebook group page between June 30, 2014, and June 30, 2015. A total of 159 posts were posted by 19 cohort members. Cohort member I was not a member of the Facebook group, and cohort members B, C, G, P, and X were members of the group but did not post anything to the group page. Among the posters, as shown in Table 1, cohort member $\mathrm{H}$ contributed the most-more than one fourth of all the posts. In fact, the top three posters, members $\mathrm{H}, \mathrm{D}$, and $\mathrm{W}$, collectively contributed close to half of all the posts.

Figure 1 reveals that July 2014, the month immediately following the 2014 IRDL, witnessed the most postings from the cohort members. There were almost twice as many as during the second most frequently posted month.

Regarding the content of the posts, the following themes emerged:

- The majority of the posts $(40.9 \%)$ were about the individual project that each cohort member is expected to complete as part of his or her IRDL experience. Below are a few examples:

Updates on research progress: "I have 9 of 12 IDIs scheduled over the next couple weeks! Fingers crossed all the technology works."

- Seeking help: "Help! My study involves a pre- and post-session survey and I got a great number of pre-session responses (97). However, despite advertising in the same way, I only have 10 post-session responses and I'd like to close it at the end of next week. Any suggestions for boosting this number?"

Sharing feelings: "Currently at the stage of research where I'm convinced I'm stupid and my study is even more stupid. Does that happen to everyone, or just me?"

- In second place were posts (17.6\%) announcing research-related resources, 
such as articles and book chapters related to research methods, venues (such as conferences and journals) for disseminating research findings, funding opportunities, and professional development opportunities.

- $\quad$ Only 13.8 percent of the posts were about other research projects and practices that the cohort members were engaged in beyond their IRDL research project. Below are a few examples:

Asking questions: “Hi folks, I've been reviewing a few papers for colleagues and other documents, and I have a question about commenting etiquette for our field."

Sharing news/experiences: "Hi folks, I just wanted to share my experience with a 2 day NVivo training workshop. If you're interested, just send me an e-mail and I can send you the PowerPoints for the workshop."

- A total of 10.7 percent of the posts were specific to cohort members' IRDL experiences, where they reflected on what they learned at IRDL, discussed how they shared their IRDL experiences with others, and expressed reminiscent sentiments about IRDL.

- Just over 1 in 10 (10.1\%) of the posts were about attending conferences - cohort members were seeking co-presenters or roommates and arranging for meetups.

- A small portion of the posts (3.1\%) were addressed to individual members rather than the whole group; for example, a cohort member addressed a post to three other members who were his co-authors on a published article and asked how to track the citations to their article.

- The last two categories each contained 1.9 percent of the posts: announcements of information not related to research (such as job posts), and work-related questions (for instance, how to schedule reference desk hours).

\section{Online Survey}

An online survey was conducted among the IRDL 2014 cohort to examine their perception of the Facebook group as an online community for the cohort members to remain connected after they exit the situational relationship formed during the two-week IRDL training. Since the purpose of the survey was to uncover how the cohort members perceive a research-oriented online community, we decided to focus on Facebook exclusively and exclude Twitter because the content analysis showed most the tweets $(41.9 \%)$ were not pertinent to research or to IRDL.

The link to the survey was e-mailed to all 25 cohort members, out of whom 19 completed the questionnaire. Among them, one member indicated that he/she never used Facebook, leaving the total number of valid responses to be 18 .

The first survey question sought to understand cohort members' general use of Facebook. They were asked to indicate how frequently they visit Facebook to check updates, using a slider ranging from 1 (never) to 5 (more than once a day). The average frequency rating was 3.9. It's also worth noting that 46.7 percent of the respondents selected 5, meaning that the majority of them were frequent Facebook users.

Regarding how they view updates on the "IRDL Scholars" Facebook group page, percent chose "I view it after I receive notifications about updates on the page," and 44.4 percent chose "I view it only when I happen to be on Facebook."

To understand cohort members' attachment to the Facebook group, they were presented with two statements: "I identify with what the group represents-librarian scholars who conduct and/or disseminate quality research" and "I have personal connections with some members of the group." The majority $(81.3 \%)$ indicated that both statements accurately described their group attachment, 6.3 percent felt that the former statement was a more accurate description, and 12.4 percent chose neither and 
explained that the Facebook group was simply the easiest way for them to keep in touch with other cohort members and obtain support for their research.

Regarding cohort members' satisfaction with Facebook group page, four different aspects were examined: content of the posts, quantity of posts, Facebook as the online venue for the group to stay connected, and overall helpfulness of the group page to their research progress. A 5-point Likert scale (1 being very dissatisfied, and 5 being very satisfied) was used to record the responses. As shown in figure 2, the cohort members had relatively high levels of satisfaction with the Facebook group page: they were most satisfied with the content of the posts and least satisfied with the page's overall helpfulness to their research progress.

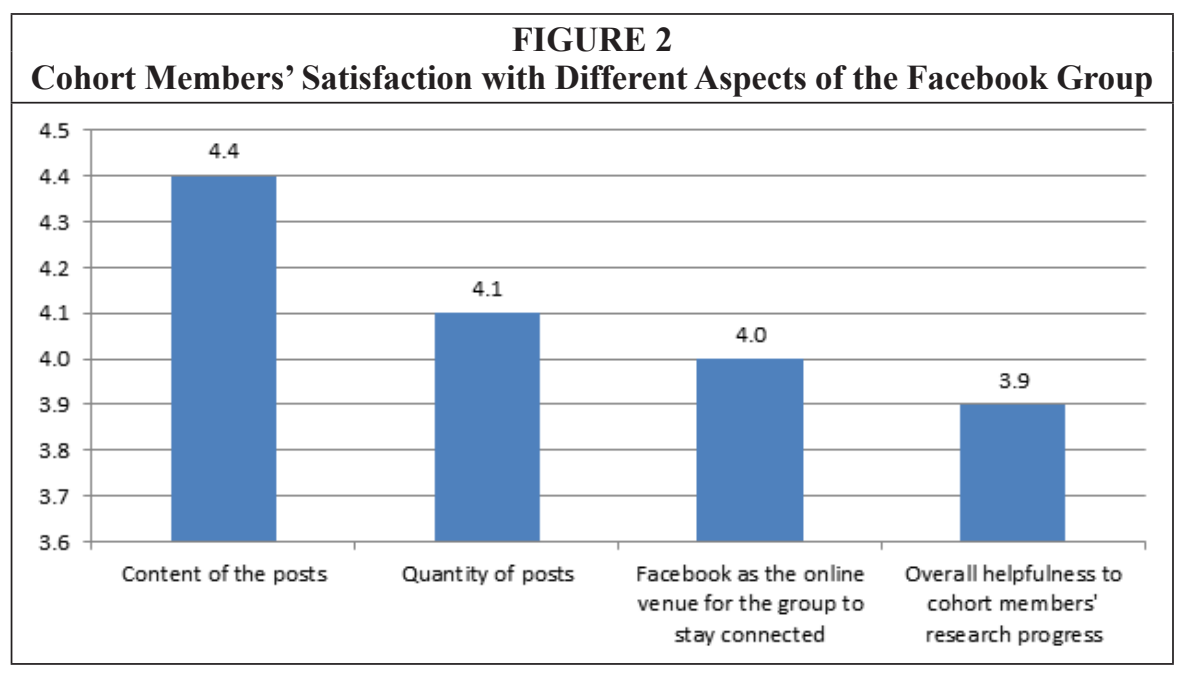

An open-ended question was placed at the end of the survey to elicit input on the elements of an ideal online community for librarian researchers. The following ideas were mentioned in the cohort members' responses:

- Participants of the community having diverse research areas and research experiences

- A variety of relevant information being shared, such as status of current projects, challenges being faced, upcoming opportunities, and requests for collaboration or assistance

- $\quad$ Private, and safe to ask questions and seek support

- $\quad$ Easy to access

- Having advanced search functionality so that notifications can be customized and past posts can be easily searched

- Offering a sense of personal connection (such as through shared experiences, in-person meetings)

- $\quad$ Active but not overwhelming

In addition to the above shared ideas, there was also a conflict of opinions. Some cohort members liked integrating the online community with their daily social network activities (such as using Facebook) because it provides a more casual way of communicating and reduces the barrier to participation. Some others felt that the online community should be independent of social media (like using e-mail instead) because they were concerned about Facebook's privacy policies and would like to have more 
of a division between "work" life and "home" life. Still, they admitted that having a Facebook group is "better than nothing."

\section{Discussion}

Most of the IRDL 2014 cohort members were participating in the online community, and there were only two who did not have any presence on either Twitter or Facebook. Some members were more active on the Facebook group page, and some others were more active on Twitter. For example, members A, N, O, T, and X participated in the Facebook group but did not send any tweets; member $\mathrm{H}$ was the most frequent poster on Facebook but contributed only one tweet. On the other hand, the most active contributor on Twitter, member $S$, sent 21.5 percent of the tweets, compared to only 5.0 percent of the Facebook posts. On Facebook, members C, G, P, and X did not post anything, but they participated via "Likes" or responses. The variety of posting behavior shows that the cohort members have different patterns of engaging in the online community; some may be more active in initiating posts, and others may feel more comfortable with just responding to what is posted; and some may prefer one social media venue over another. The discrepancies of preferences were also reflected in their responses to the online survey, where some cohort members appreciated the use of a social media platform like Facebook to host the online community, and some others felt a platform separate from social media would have been more appropriate. Given the varying behavior and preferences among individuals, when designing online communities for librarian researchers, it would be helpful to investigate what potential participants need or desire in terms of the venue, form, and setup of the online community. As the community develops, the participants' needs and desires may also evolve; thus it is important to provide a channel for them to voice their input, based on which design of the online community can continue to improve. In their discussion of online communities' lifecycle, Iriberri and Leroy ${ }^{35}$ also identified user-centered design and evolution as a success factor at the creation stage of an online community.

It is worth noting that the IRDL online community participation peaked in July 2014, which was the first month after the IRDL onsite training. After that, both Facebook and Twitter posts had been dropping. This could be attributed to the fact that the community was small and only consisted of the 25-member 2014 IRDL cohort. The 2015 cohort members were later added to the Facebook page, but not until the end of the time period covered by this study. Iriberri and Leroy, ${ }^{36}$ when discussing the growth stage of the online community lifecycle, pointed out the importance of reaching a critical mass and integrating new members. But both conditions were lacking in the IRDL online community, which may have contributed to the decline in participation.

In the online survey, most the members indicated that they both identify with what the group represents: librarian scholars who conduct and/or disseminate quality research and have personal connections with some members of the group. According to Ren et al., ${ }^{37}$ both common identity and common bond theory apply here. Common identity in the online context implies that members feel committed to the online community's purpose or topic, and common bond suggests that members feel socially or emotionally attached to particular members of the online community. On one hand, the cohort members have the shared identity the online community is dedicated tolibrarian researcher; on the other hand, their shared IRDL experience serves as a bond that provides personal connections in the online community. When the 2015 cohort was added to the Facebook group page, even though they feel a commitment to the common identity, they do not share the common bond with the 2014 cohort, which may have posed challenges to their integration to the community and made them reticence to participate. Thus, when designing online communities for librarian researchers, it 
is important to understand members' attachment to the group when integrating new members and make design decisions accordingly. If the community is more identitybased efforts should be made toward helping newcomers navigate through information traffic, understand community norms, and engage in community conversations in meaningful ways. If the community is more bond-based, the focus needs to be on assisting newcomers in connecting with existing members, joining group interactions, and forming lasting relationships with a subset of community members. ${ }^{38}$

In terms of the content of online posts, Facebook and Twitter had the following overlap: 1) posts related to completing the IRDL research project required for each cohort member; 2) announcements about research-related resources and opportunities; posts reminiscing about the IRDL experience; and 4) arrangements of conference attendance and meetups. These four categories provide a glimpse of the popular topics an online community for librarian researchers may be interested in. This knowledge may help online community designers better understand how to initiate and monitor discussions on relevant topics. Iriberri and Leroy ${ }^{39}$ considered content quality as one of the success factors for the growth stage of the online community life cycle, and knowing what types of content might be appealing to the community is an important first step in ensuring content quality.

Overall, the cohort members were satisfied with different aspects of the online community on Facebook. Their satisfaction with the content of the Facebook posts was the highest, indicating that they were most satisfied with the issues or topics being discussed. Wang et al. ${ }^{40}$ discovered that member commitment in online communities is heavily influenced by members' issue involvement. This echoes the aforementioned importance of content quality in Iriberri and Leroy, ${ }^{41}$ reinforcing the need to keep community members engaged in the discussion of relevant, meaningful, and interesting topics when designing online communities for librarian researchers.

Steuer's ${ }^{42}$ communication model described how communication occurs not only between one individual and another, but also between individuals and the mediated environment with which they interact. Thus, in online communities, the technology interface perspective is necessary to consider. In the case of the IRDL online community, the cohort members reported a relatively high level of satisfaction with using Facebook as the online community platform. Still, some of them pointed out its limited functionalities such as the difficulty in archiving, searching, and retrieving old posts. When designing online communities for librarian researchers, it is imperative to adopt an interface that meets all the user requirements and yet is stable, intuitive, and easy to use.

Toral et al., ${ }^{43}$ when studying the driving forces behind online communities, observed that "understanding what makes online communities successful is quite complicated." We hope the findings of our study will contribute to the challenging and yet worthy quest to unearth effective and efficient ways to establish and grow online communities for librarian researchers. We are aware of the small size and special circumstances of the IRDL online community under study, which may limit the generalizability of the results. Future research may reach beyond limitations and focus on the development and evaluation of online communities for librarian researchers on a larger scale. For instance, in evaluation studies, it would be interesting to compare participants' actual experience with the intended goals of the community and to investigate how participants' experiences in research-focused communities differs from their experiences in other kinds of online librarian communities. If an online community is reasonably large and meaningful sub-groups have formed, sub-community activities could be examined to obtain a more granular view of online communities for librarian researchers.

Since there has not been any previous research on online librarian communities in general, our study may also help generate conversations about the role of online 
communities in assisting librarians' professional growth and encourage more research in this area. In addition, funding agencies may draw upon our findings to determine what kinds of online communities have the potential to succeed so that they could make more judicious and proper funding decisions. Furthermore, librarians who are responsible for supporting faculty research may draw ideas from our study to help faculty form online communities to expand their research network and advance their research agenda.

\section{Conclusion}

In this rapidly changing world, academic librarians undertake their own research to meet "the need for more information for use in decision making at the managerial level, the need to keep abreast of new knowledge and procedures in this information society, and the need for continuing education and upgraded qualifications." ${ }^{44}$ Online communities provide opportunities for librarians to interact with each other and support each other in the process of conducting and disseminating research to enhance practices. They offer a sense of camaraderie and belonging and can help librarian researchers overcome the numerous barriers they face in their research journey. In this study, through a descriptive case study of the IRDL online community, we make the first effort in understanding the role of online communities in connecting and supporting librarian researchers, and we hope it will lead to more scholarly conversations and empirical studies about this important topic.

\section{Notes}

1. Gay H. Perkins and Amy Slowik, "The Value of Research in Academic Libraries," College $\mathcal{E}$ Research Libraries 74, no. 2 (2013): 143-58.

2. Ronald R. Powell, Lynda M. Baker, and Joseph J. Mika, "Library and Information Science Practitioners and Research," Library and Information Science Research 24, no. 1 (2002): 50.

3. Albert Bandura, "Self-efficacy," in Encyclopedia of Human Behavior, ed. V.S. Ramachaudran (New York: Academic Press, 1994), 71-81.

4. Peter Hernon and Candy Schwartz, "Can Research Be Assimilated into the Soul of Library and Information Science?" Library and Information Science Research 17 (1995): 102.

5. Ellen Crumley and Denise Koufogiannakis, "Developing Evidence-based Librarianship: Practical Steps for Implementation," Health Information E Libraries Journal 19, no. 2 (2002): 61-70.

6. Gaby Haddow and Jane E. Klobas, "Communication of Research to Practice in Library and Information Science: Closing the Gap," Library and Information Science Research 26, no. 1 (2004): 29-43.

7. James G. Neal, "The Research and Development Imperative in the Academic Library: Path to the Future," portal: Libraries and the Academy 6, no. 1 (2006): 1-3.

8. Perkins and Slowik, "The Value of Research in Academic Libraries," 143-58.

9. Dale Montanelli and Patricia E. Stenstrom, "The Benefits of Research for Academic Librarians and the Institutions They Serve," College E Research Libraries 47, no. 5 (1986): 482-85.

10. Stefanie Dubose and David Durant, "Research and Practice in Academic Libraries: A Case Study," North Carolina Libraries 59, no. 1 (2001): 4-9.

11. Perkins and Slowik, "The Value of Research in Academic Libraries," 143-58.

12. Donald E. Riggs, "Losing the Foundation of Understanding," American Libraries 25, no. 5 (1994): 449.

13. Lynne McKechnie, Heidi Julien, and Tami Oliphant, "Communicating Research Findings to Library and Information Science Practitioners: A Study of ISIC Papers from 1996 to 2000," Information Research 13, no. 4 (2008): 7.

14. Haddow and Klobas, "Communication of Research to Practice in Library and Information Science," 29-43.

15. T.J. Waldhart, “Editorial,” Library Research 2 (1980): 105. 50.

16. Powell, Baker, and Mika, "Library and Information Science Practitioners and Research,"

17. Kathlyn Turner, "Do Information Professionals Use Research Published in LIS Journals?" (presentation, IFLA Council and General Conference, Glasgow, August 18-24, 2002).

18. Pat Molholt, "Structuring Models of Research for Information Science: Attitudes, Percep- 
tions and Values" (presentation, Samuel Lazerow Memorial Lecture at the University of Pittsburgh, Pittsburgh, PA, 1998).

19. Johannes Balslev, "A Working Librarian's Experience with Library Research," Scandinavian Public Library Quarterly 4, no. 4 (1989): 4-9.

20. Charles McClure and Ann Bishop, "The Status of Research in Library and Information Science: Guarded Optimism," College E Research Libraries 50, no. 2 (1989): 135.

21. J. Basker, "What Librarians Need from Researchers," New Library World 86, no. 8 (1985): $147-148$.

22. Rebecca Watson-Boone, "Academic Librarians as Practitioner-Researchers," Journal of Academic Librarianship 26, no. 2 (2000): 85-93.

23. Bill Crowley, Spanning the Theory-Practice Divide in Library and Information Science (Oxford, U.K.: Scarecrow Press, 2005).

24. Fion Lee, Douglas Vogel, and Moez Limayem, "Virtual Community Informatics: A Review and Research Agenda," Journal of Information Technology Theory and Application 5, no. 1 (2003): 51.

25. Alicia Iriberri and Gondy Leroy, "A Life-cycle Perspective on Online Community Success," ACM Computing Surveys 41, no. 2 (2009): 1-29.

26. Ibid., 1 .

27. Catherine M. Ridings, David Gefen, and Bay Arinze, "Some Antecedents and Effects of Trust in Virtual Communities," Journal of Strategic Information Systems 11, no. 3 (2002): 271-95; Chin-Lung Hsu and His-Peng Lu, "Consumer Behavior in Online Game Communities: A Motivational Factor Perspective," Computers in Human Behavior 23, no. 3 (2007): 1642-59; Meng-Hsiang Hsu, Teresa L. Ju, Chia-Hui Yen, and Chun-Ming Chang, "Knowledge-sharing Behavior in Virtual Communities: The Relationship Between Trust, Self-efficacy, and Outcome Expectations," International Journal of Human-Computer Studies 65, no. 2 (2007): 153-69; Joon Koh, Young-Gul Kim, Brian Butler, Gee-Woo Bock, "Encouraging Participation in Virtual Communities," Communications of the ACM 50, no. 2 (2007): 69-73; Sergio Toral, M. Rocío Martínez-Torres, Federico Barrero, and Francisco Cortés, "An Empirical Study of the Driving Forces behind Online Communities," Internet Research 19, no. 4 (2009): 378-92; Tao Zhou, "Understanding Online Community User Participation: A Social Influence Perspective," Internet Research 21, no. 1 (2011): 67-81.

28. Iriberri and Leroy, "A Life-cycle Perspective on Online Community Success," 1-29.

29. Pamela Ludford, Dan Cosley, Dan Frankowski, and Loren Terveen, "Think Different: Increasing Online Community Participation Using Uniqueness and Group Dissimilarity," CHI 2004 Proceedings 6, no. 1 (2004): 631-38.

30. Edward Wang, Lily Chen, and Bi-Kun Tsai, “Investigating Member Commitment to Virtual Communities Using an Integrated Perspective," Internet Research 22, no. 2 (2011): 199-210.

31. Yuqing Ren, Robert Kraut, and Sara Kiesler, "Applying Common Identity and Bond Theory to Design of Online Communities," Organization Studies 28, no. 3 (2007): 377-408.

32. William J. Goode and P.K. Hatt, Methods in Social Research (London, U.K.: McGraw-Hill, 1952).

33. Robert K. Yin, Case Study Research: Design and Methods (Thousand Oaks, Calif.: SAGE Publications, 2014).

34. David de Vaus, Research Design in Social Research (London, U.K.: SAGE Publications, 2001).

35. Iriberri and Leroy, "A Life-cycle Perspective on Online Community Success," 1-29.

36. Ibid., 21.

37. Ren, Kraut, and Kiesler, "Applying Common Identity and Bond Theory to Design of Online Communities," 377-408.

38. Ibid., 401.

39. Iriberri and Leroy, "A Life-cycle Perspective on Online Community Success," 1-29.

40. Wang, Chen, and Tsai, "Investigating Member Commitment to Virtual Communities," 199-210.

41. Iriberri and Leroy, "A Life-cycle Perspective on Online Community Success," 1-29.

42. Jonathan Steuer, "Defining Virtual Reality: Dimensions Determining Telepresence," Journal of Communication 42, no. 4 (1992): 73-93.

43. Toral, Martínez-Torres, Barrero, and Cortés, "An Empirical Study of the Driving Forces behind Online Communities," 379.

44. Peter Jarvis, The Practitioner-Researcher: Developing Theory from Practice (San Francisco, Calif.: Jossey-Bass Publishers, 1999), 7. 